\section{Asparagopsis in Europe}

THE spread of Asparagopsis in Europe has rightly attracted considerable attention, but tho excitement with which each now record has been greeted has tended to obscure certain unanswered questions regarding two species at present accepted, $A$. armata Harv. and $A$. taxiformis (Delile) Trev.

Montagne ${ }^{1}$ based the original treatment of the genus on Fucus taxiformis Delile ${ }^{2}$, although changing the epithet to the illegitimate delilei; the combination Asparagopsis taxiformis, usually credited to Collins and $\mathrm{Hervey}^{3}$, was, in fact, used by Trevisan ${ }^{4}$ and afterwards overlooked. A. taxiformis has been reported widely from the tropical waters of the Pacific, Indian and Atlantic Oceans, the most northerly records in the latter being from Bermuda, the Canary Islands, and possibly the Azores ${ }^{5}$, although the latter report has been questioned ${ }^{6}$. A. taxiformis has also been reported from the Mediterranean, where it is said to be restricted to the eastern region. A.part from some observations by Schiffner?, which have been disputed, there appears to be only one record, from Algeria, of the occurrence of $A$. taxiformis as such in the western Mediterranoan, and that is based on a drift specimen thought to have originated in the eastern region ${ }^{8}$ However, it should be noted that the type locality for Falkenbergia hillebrandii, the alternate phase in the lifehistory of Asparagopsis taxiformis, is the Island of Elba, and there are other early reports ${ }^{8}$ of the occurrence of this entity in the western Mediterranean. Asparagopsis armata was first described from Australia during the last century and specimens referred to this species were first identified in Europe some forty years ago. Further reports of its occurrenco in various localities in north-west Europe and North Africa have been made over the years, but there is still a marked disjunction in tropical waters between the European and Australian areas of distribution.

The first question to be answered concerns the relationship between $A$. armata and $A$. taxiformis. From the literature $e^{6,10}$ it would appear that the only difference between the two alga $\Theta$ is the occurrence of branches bearing spines in the former. The type material of $A$. armata is now preserved in the herbarium of Trinity College, Dublin, and, although the present location of Delile's type specimens is unknown"1, part at least of Delile's original collection of $A$. taxiformis has been found in the Lamouroux Herbarium during a visit to the Institut Botanique, Caen. Examination of these type materials and of other collections confirms that the presence or absence of spinebearing branches is the only criterion by which the two entities can be distinguished. $A$. taxiformis and $A$. armata havo been accepted as distinct species by all authors except Schiffner ${ }^{7}$, who considered them merely as growth forms of a single species.

Schiffner's observations have been ignored or dismissed as the erronoous interpretation of badly prepared speci. mens $^{10}$, but some recent personal observations indicate that further investigation of the production of spinc-bearing branches in this genus is necessary. During the past few years, several specimens of Asparagopsis in which the spine-bearing branches characteristic of $A$. armata were very reduced in size and number have been collected at various localities on the south and west coasts of Britain and Ireland, while in a single collection from the Tsles of Scilly no trace of the spine-bearing branches could be found so that the fronds were otherwise indistinguishable from those referred to $A$. taxiformis. In connexion with this problem, it should be noted also that there are no apparent morphological differences between Falkenbergia rufolanosa and $F$. hillebrandii, the alternate phases in the life-histories of $A$. armata and $A$. taxiformis respectively.

The second question relates to the origin of the Furopean material referred to $\boldsymbol{A}$. armata. It has been accepted universally that the European material was initially of
Australian origin but, in view of the doubts as to the relationship between $A$. taxiformis and $A$. armata, a reconsideration of the origin of the European material is warranted. Whether this can now be undertaken depends very largely on the extent to which the taxonomic problem can be elucidated.

The third question concerns the life-history of the entity in the British Isles. Tetrasporangia have nover been detected in the Falkenbergia phase in Britain or Ireland, while plants of the Asparagopsis phase with carpospores appear to be diminishing in frequency ${ }^{12}$. The barbed branches of tho Asparagopsis phase facilitate vegetative propagation and the floating 'balls' of the Falkenbergia phase, which occur so abundantly on occasions in British waters, have been observed to re-attach with ease ${ }^{13}$. The now attachment is relatively weak and the 'ball' is readily detached so that it may well be moved on many times during its life. These observations suggest that in dependent propagation of both the Asparagopsis and Falkenbergia phases is occurring and that the actual life-history of the entity in British waters may not be the functional sequence of sexual, carposporic and tetrasporic phases demonstrated in other areas ${ }^{14}$. It is probable that this independent vegetative propagation is a likely explanation for the small differences in geographical distribution of the two phases which have become increas ingly marked during recent years and which have been attributed by various authors ${ }^{15,16}$ to differences in ecological requirements.

These three questions demonstrate the deficiencies in our knowledge of Asparagopsis, which is by no means as complete as is often assumed. By directing attention to tho crucial problem of the relationship between $A$. taxi. formis and $A$. armata it is hoped that further investigations will provide the answers to this, and the related problems. In this connexion, reports of the occurrence of spineless specimens of Asparagopsis in Britain will be particularly valuable.

\section{Hartley Botanical Laboratories,} University of Liverpool. \footnotetext{
'Montagne, C., Plantes cellulaires, in Barker-Webb, P., and Berthelot, S.
Histoire naturelle des Iles Canaries, 3 (2), Sect. Ult. (Paris, 1841).

2 Delile, A. R., Flore de l'Egypte (Paris, 1813).

'Collins, F. S., and Hervey, A. B., Proc. Amer. Acad. Arts Sci., 53, 1 (1917).

- Trevisan, V. B. A., Nomenclator algarum, . . ., 1 (Padua, 1845)

'Schmidt, O. C., Bibl. Bot., 102, 1 (1931).

- Feldmann, J., and Feldmann, G., Ann. Sci. Nat. (Bot.), Ser. 11, 3, 75 (1942)

' Schiffner, V., Hedwigia, 71, 139 (1931).

B Foldmann, J., and Feldmann, G., Bull. Soc. Hist. Nat. Afr. N., 30, 453 (1939).

- Preda, A., Flora Italica cryptogama, pars Ir Algae, 1 (2), (Rome, 1908).

${ }^{10}$ Feldmann, J., Rev. Algol., 11, 247 (1939).

11 Dawson, E. Y., Allan Hancock Pacif. Exped., 17 (1), 1 (1953).

12 De Valera, M., and Folan, A., Brit. Phycol. Bull., 2 (in the press).

13 Dixon, P. S. (unpublished results).

10 Chihara, M., Sci. Rep. Tokyo Kyoiku Daigaku, Sect R, 10, 121 (1961); 11, 27 (1962).

1s Thornas, L., Coll. bot. Barcinone, 4, 399 (1955).

19 Conway, E., Nature, 186, 566 (1960).
}

\section{Mechanism for Nitrogen-increased Shoot/ Root Ratios}

AbErg's review' ${ }^{1}$ cites Söding (Die Wuchstofflehre, Goorg Thieme Verlag, Stuttgart, Germany, 1952) as suggesting that the generally recognized inereased shoot/root ratios resulting from nitrogen fertilization are caused by nitrogenincreased growth hormone content which, in turn, inhibits root growth and promotes shoot growth in the intact plant. This suggestion appears reasonable and was supported by Bosemark ${ }^{2}$, who compared the growth of roots in high nitrogen solution with that of roots growing in solutions containing growth hormones.

Strong exporimental support for this hypothesis was obtained from two experiments conducted in this Labora- 